\title{
Etching of GaAs substrates to create As-rich surface
}

\author{
A CHANDA, S VERMA ${ }^{\dagger}$ and C JACOB* \\ Materials Science Centre, Indian Institute of Technology, Kharagpur 721 302, India \\ ${ }^{\dagger}$ Institute of Physics, Bhubaneswar 751 005, India
}

MS received 9 April 2007; revised 9 October 2007

\begin{abstract}
Several different cleaning procedures for GaAs (100) substrates are compared using X-ray photoelectron spectroscopy and optical microscopy. This work emphasizes the effect of the last etching step: using either $\mathrm{HCl}, \mathrm{HF}-$ ethanol $(5 \%)$ or static deionized water after $\mathrm{HCl}$ cleaning. All the procedures except $\mathrm{HCl}$ solution (1: 1) produce an As-rich surface. Also, none of the etchants except HF-ethanol solution produce Ga or Asrich (oxide free) surfaces. Optical microscopic study shows different etch pits produced due to etching in different solutions.
\end{abstract}

Keywords. Etching; semi-insulating; XPS spectrum.

\section{Introduction}

In the last few decades, several XPS studies have been published on the effects of different etching procedures of GaAs (Chang et al 1977; Bertrand 1981; Vasquez et al 1983a, b). The most common etching method used for GaAs substrates is chemical etching based on an $\mathrm{H}_{2} \mathrm{SO}_{4} /$ $\mathrm{H}_{2} \mathrm{O}_{2} / \mathrm{H}_{2} \mathrm{O}-\mathrm{HCl}$ etching, followed by an ultimate rinse in deionized water which is supposed to produce a thin passivating oxide film. This oxide layer is less reactive towards carbonaceous species than the naked GaAs surfaces and thus preserves the etched surface from contamination during the manipulations of the substrate after the chemical etching process. This procedure, previously described by Cho and coworkers (Cho and Tracy 1976; Cho et al 1980; Cho 1983) is presently used by most groups. The present work has been done with the intention of creating an As-rich GaAs surface on which Mn could be deposited and annealed so as to produce a MnAs layer on a GaAs surface. MnAs is a room temperature ferromagnet $\left(T_{\mathrm{C}}\right.$, $318 \mathrm{~K}$ ) and the integration of ferromagnetic material with a semiconductor has wide use in spintronics devices. Also, MnAs which shares common atoms with GaAs is thermodynamically and morphologically stable on GaAs. Although a lot of work has been done on the etching of GaAs surface, this study was undertaken in order to confirm which procedure is suitable to produce an As-rich surface. The present study deals with the characterization of GaAs (100) surfaces by X-ray photoelectron spectroscopy (XPS) processed with different solutions.

\footnotetext{
*Author for correspondence (cxj14_holiday@yahoo.com)
}

\section{Experimental}

Semi-insulating undoped GaAs (100) substrates with resistivity, $1 \times 10^{7} \mathrm{ohm}-\mathrm{cm}$, were used. The surfaces were originally covered with native oxides. Four different cleaning procedures were used. Two samples were rinsed in acetone, methanol and deionized water and then etched in $\mathrm{H}_{2} \mathrm{SO}_{4}: \mathrm{H}_{2} \mathrm{O}_{2}: \mathrm{H}_{2} \mathrm{O}:: 5: 1: 1$ for $10 \mathrm{~min}$. Then, one sample was dipped in concentrated $\mathrm{HCl}$ for $5 \mathrm{~min}$ while the other sample was dipped in $\mathrm{HF}$ at a concentration of $5 \%$ in ethyl alcohol for 2 min and then both were rinsed in deionized water. Another sample was prepared by treating $\mathrm{GaAs}$ wafer in $\mathrm{HCl}$ solution for $10 \mathrm{~min}$. The last sample was treated with $\mathrm{HCl}$ solution $(1: 1)$ for $10 \mathrm{~min}$, then in deionized water for $10 \mathrm{~s}$. After treating with different solutions, these substrates were dried in a stream of dry nitrogen. XPS analysis was carried out in a VG Microtech-ESCA2000 Multilab instrument. When recording spectra, the pressure in the chamber was around 2$5 \times 10^{-9}$ Torr. The polar emission angle, defined as the take-off angle of emission of photoelectrons from a surface, was $90^{\circ}$. All the spectra were recorded using $\mathrm{MgK}_{\alpha}$ radiation $(1253.6 \mathrm{eV})$. The binding energies were calibrated from the $\mathrm{C} 1 s$ level taken at $284.6 \mathrm{eV}$. The spectra are analysed with a curve fitting program for WIN95/98 XPSPEAK Version 4.1 [Kwok] using Gaussian and Lorentzian functions and the background was calculated according to Shirley's method (Shirley 1972; Sherwood 1984). An optical microscope (Leica DMLM) was used to study the surface morphology at different magnifications.

\section{Results and discussion}

Figures 1-3 show the spectra obtained for $\mathrm{Ga}$, As and $\mathrm{O}$ using the four techniques described in table 1 and for an 
untreated GaAs surface. Inset in figures 1-3 shows the peak fit of $\mathrm{Ga}$, As and $\mathrm{O}$ spectra of untreated GaAs. The numbers 1-4 in figures 1-3 indicate the techniques used. Table 2 shows the peak positions, area and corresponding FWHM of different peaks taken for curve fitting of $\mathrm{Ga}$ and As peaks.

\subsection{Untreated GaAs}

Ga $3 d$, As $3 d, \mathrm{C} 1 s, \mathrm{O} 1 s$ XPS peaks were measured for the as received $\mathrm{GaAs}$ wafer before chemical etching. O1s signal corresponds to a mixture of $\mathrm{Ga}_{2} \mathrm{O}_{3}$ and $\mathrm{As}_{2} \mathrm{O}_{3}$. The $\mathrm{Ga} 3 d$ peak at a binding energy of $21.4 \mathrm{eV}$ was assigned to the oxide and that at $20 \cdot 04 \mathrm{eV}$ to the bulk GaAs. The ratio of oxidized $\mathrm{Ga}$ over total $\mathrm{Ga}$ atoms calculated from deconvoluted peak area is $0 \cdot 30$. The ratio of the inte-

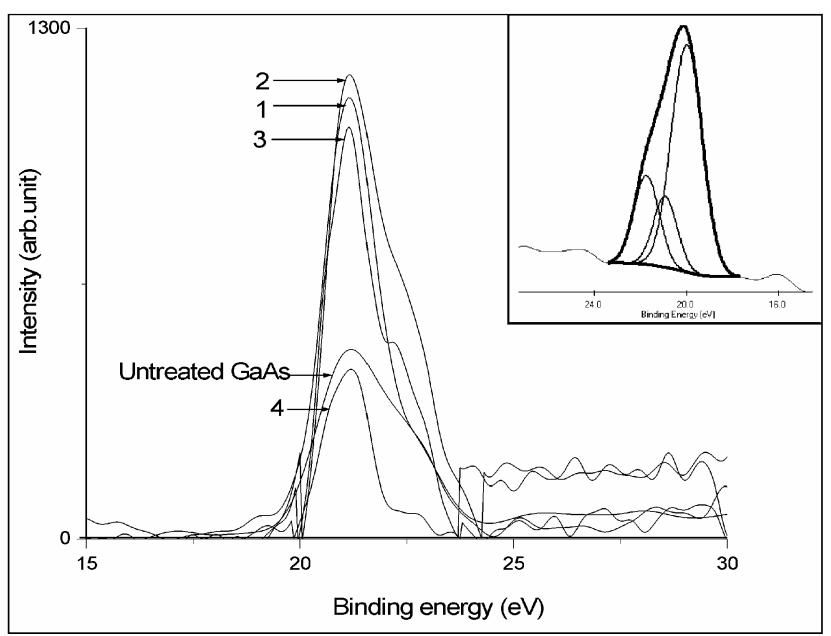

Figure 1. XPS spectra of Ga obtained using procedures 1-4 as described in table 1.

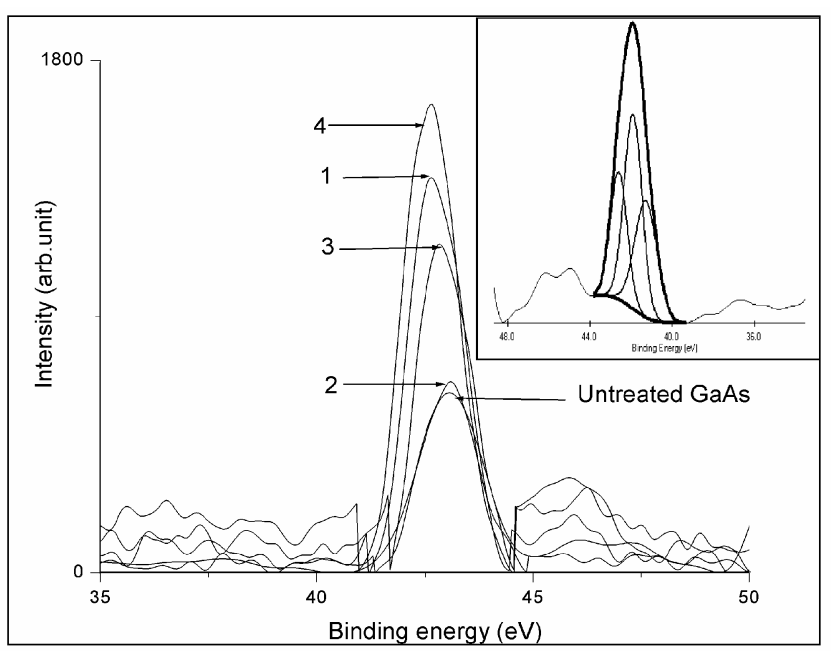

Figure 2. XPS spectra of As obtained using procedures 1-4 as described in table 1 . grated areas of $3 d$ As and $3 d$ Ga peaks, calculated considering both substrate and oxidized phase atoms, is 0.99 which is very near to 1 which means untreated GaAs is neither Ga-rich nor As-rich. Both Ga and As atoms are equally distributed.

\subsection{GaAs treated in $\mathrm{H}_{2} \mathrm{SO}_{4} / \mathrm{H}_{2} \mathrm{O}_{2} / \mathrm{H}_{2} \mathrm{O}:: 5: 1: 1$ and then in conc. $\mathrm{HCl}$ for 5 min and then in deionized water}

Using this procedure, the chemical shifts measured on Ga and As levels are close to $2 \mathrm{eV}$ for $3 d$ levels. An important contribution from the surface oxygen bound atoms is observed. This contribution is more clearly detected on $\mathrm{Ga}$ atoms. No trace of oxidation is observed on the As $3 d$ level, which is most sensitive to superficial chemical reactions. The ratio of oxidized $\mathrm{Ga}$ atoms to total $\mathrm{Ga}$ atoms is 0.36 which indicates that the surface gets oxidized after etching. Also, as the samples are not immediately put inside the XPS analysis chamber, a comparatively thick oxide surface results. The ratio of $3 d \mathrm{As}$ and $3 d \mathrm{Ga}$ atoms obtained by taking the integrated area into calculation is 0.96 which gives an As-deficient oxidized phase. However, Massies and Contour (1985) have shown that if instead of static deionized water, running deionized water is used after $\mathrm{HCl}$ dip, an As-rich deoxidized surface will be produced.

\subsection{GaAs treated in $\mathrm{HF}$ at a concentration of $5 \%$ in ethyl alcohol}

This procedure leads to a deoxidized GaAs surface i.e. the $\mathrm{Ga}$ and As atoms are not in the oxidized form. The $531.85 \mathrm{eV}$ oxide peak is due to atmospheric oxygen during substrate manipulation. The ratio of As and Ga atoms

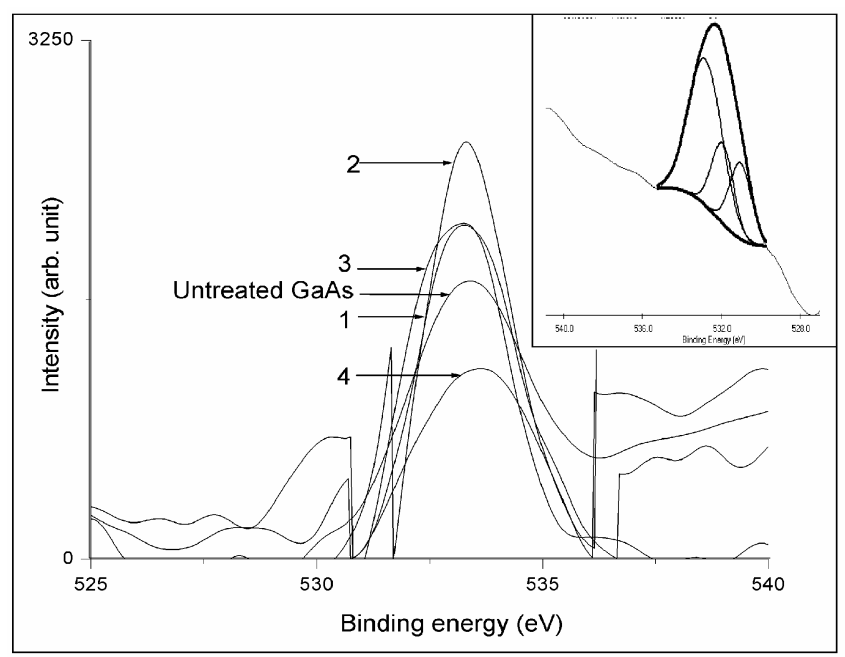

Figure 3. XPS spectra of $\mathrm{O}$ obtained using procedures $1-4$ as described in table 1 . 
Table 1. Treatment procedures used.

\begin{tabular}{|c|c|c|c|c|}
\hline \multirow[b]{2}{*}{ Techniques } & \multicolumn{4}{|c|}{ Treatment } \\
\hline & 1st stage & 2nd stage & 3rd stage & 4th stage \\
\hline 1 & $\begin{array}{l}\text { Treated with acetone, } \\
\text { methanol, DI-water }\end{array}$ & $\begin{array}{l}\mathrm{H}_{2} \mathrm{SO}_{4}: \mathrm{H}_{2} \mathrm{O}_{2}: \mathrm{H}_{2} \mathrm{O}:: 5: 1: 1 \\
\quad \text { for } 10 \mathrm{~min}\end{array}$ & $\mathrm{HCl}(5 \mathrm{~min})$ & $\begin{array}{l}\text { Rinsed in } \\
\text { DI-water }\end{array}$ \\
\hline 2 & Same as 1 & Same as 1 & $\begin{array}{l}\mathrm{HF} \text { at a conc. } \\
\text { of } 5 \% \text { in } \mathrm{C}_{2} \mathrm{H}_{5} \mathrm{OH} \\
(2 \mathrm{~min})\end{array}$ & $\begin{array}{l}\text { Rinsed in } \\
\text { DI-water }\end{array}$ \\
\hline 3 & $\mathrm{HCl}$ solution $(10 \mathrm{~min})$ & & & \\
\hline 4 & Same as 3 & DI-water for $10 \mathrm{~s}$ & & \\
\hline
\end{tabular}

Table 2. Peak positions, area, FWHM of different peaks taken to fit the Ga and As peaks using XPS peak fit 4.1 software.

\begin{tabular}{|c|c|c|c|c|c|c|c|c|}
\hline \multirow[b]{2}{*}{ Techniques } & \multicolumn{4}{|c|}{ Gallium } & \multicolumn{4}{|c|}{ Arsenic } \\
\hline & Peak & Position & Area & FWHM & Peak & Position & Area & FWHM \\
\hline 1 & $\begin{array}{l}0 \\
1\end{array}$ & $\begin{array}{l}20.775 \mathrm{eV} \\
22.230 \mathrm{eV}\end{array}$ & $\begin{array}{r}1549.215 \\
228.550\end{array}$ & $\begin{array}{l}1.363 \mathrm{eV} \\
1.191 \mathrm{eV}\end{array}$ & $\begin{array}{l}0 \\
1\end{array}$ & $\begin{array}{l}42.527 \mathrm{eV} \\
43.323 \mathrm{eV}\end{array}$ & $\begin{array}{r}1461.752 \\
685.964\end{array}$ & $\begin{array}{l}1.101 \mathrm{eV} \\
0.970 \mathrm{eV}\end{array}$ \\
\hline 2 & $\begin{array}{l}0 \\
1 \\
2\end{array}$ & $\begin{array}{l}20 \cdot 749 \mathrm{eV} \\
19 \cdot 352 \mathrm{eV} \\
19.905 \mathrm{eV}\end{array}$ & $\begin{array}{r}1374 \cdot 157 \\
657 \cdot 616 \\
524 \cdot 819\end{array}$ & $\begin{array}{l}1.903 \mathrm{eV} \\
0.845 \mathrm{eV} \\
0.899 \mathrm{eV}\end{array}$ & $\begin{array}{l}0 \\
1 \\
2\end{array}$ & $\begin{array}{l}42.469 \mathrm{eV} \\
41.319 \mathrm{eV} \\
41.933 \mathrm{eV}\end{array}$ & $\begin{array}{r}389 \cdot 221 \\
1544 \cdot 260 \\
644 \cdot 547\end{array}$ & $\begin{array}{l}0.990 \mathrm{eV} \\
1.077 \mathrm{eV} \\
0.812 \mathrm{eV}\end{array}$ \\
\hline 3 & $\begin{array}{l}0 \\
1 \\
2\end{array}$ & $\begin{array}{l}22 \cdot 320 \mathrm{eV} \\
20 \cdot 523 \mathrm{eV} \\
21.126 \mathrm{eV}\end{array}$ & $\begin{array}{r}660 \cdot 014 \\
139 \cdot 744 \\
1023 \cdot 412\end{array}$ & $\begin{array}{l}1.355 \mathrm{eV} \\
0.504 \mathrm{eV} \\
0.982 \mathrm{eV}\end{array}$ & $\begin{array}{l}0 \\
1\end{array}$ & $\begin{array}{l}43.254 \mathrm{eV} \\
42.542 \mathrm{eV}\end{array}$ & $\begin{array}{r}1116 \cdot 260 \\
724 \cdot 684\end{array}$ & $\begin{array}{l}1.224 \mathrm{eV} \\
0.935 \mathrm{eV}\end{array}$ \\
\hline 4 & $\begin{array}{l}0 \\
1 \\
2\end{array}$ & $\begin{array}{l}21.294 \mathrm{eV} \\
20.625 \mathrm{eV} \\
22.528 \mathrm{eV}\end{array}$ & $\begin{array}{l}370 \cdot 717 \\
198 \cdot 220 \\
113 \cdot 325\end{array}$ & $\begin{array}{l}0.891 \mathrm{eV} \\
0.812 \mathrm{eV} \\
1.026 \mathrm{eV}\end{array}$ & $\begin{array}{l}0 \\
1 \\
2\end{array}$ & $\begin{array}{l}44.344 \mathrm{eV} \\
42.557 \mathrm{eV} \\
43 \cdot 316 \mathrm{eV}\end{array}$ & $\begin{array}{r}41.933 \\
404.762 \\
658.203\end{array}$ & $\begin{array}{l}0.522 \mathrm{eV} \\
1 \cdot 048 \mathrm{eV} \\
1 \cdot 144 \mathrm{eV}\end{array}$ \\
\hline
\end{tabular}

obtained from the total peak areas is 1.07 which gives a slightly As-rich surface.

\subsection{GaAs treated with $\mathrm{HCl}$}

From As $3 d$ and Ga $3 d$ peaks, the ratio of their area is 1.7 which gives an As-rich surface. No oxides of As are present on the surface. The repeated chemical species on the $\mathrm{GaAs}$ surface etched with $\mathrm{HCl}$ solution were a mixture of gallium oxides and chlorides (Song et al 1994). But in this case, only oxidized $\mathrm{Ga}$ is obtained and the ratio of this with the total $\mathrm{Ga}$ atoms from the deconvoluted peaks is $0 \cdot 17$.

\subsection{GaAs treated with $\mathrm{HCl}$ and water}

The ratio of As and Ga signal obtained from the ratio of the total area is 1.21 which indicates an As-rich surface. Also the ratio of gallium oxide to the total gallium from the deconvoluted spectra is $0 \cdot 13$. Song et al (1994) have shown that almost all oxides and chlorides were removed from the surface by the short rinse with water after $\mathrm{HCl}$ etching. But in this study, the surface is not completely free of oxides. Although, there is no arsenic oxide (as these are soluble in water), there are still some oxides due to gallium (as gallium oxide is not soluble in water).

When the GaAs with some native oxide is immersed in $\mathrm{HCl}$ solution, the thick overlayer of oxides reacts with $\mathrm{HCl}$ and most of the oxides dissolve into the solution leaving a mixture of gallium chlorides and oxychlorides on the surface. When the GaAs substrate is subsequently dipped in water for several seconds, the surface species (gallium chlorides and oxychlorides) dissolve leaving an As-rich surface. However, in this case some oxide species due to gallium are still present which may be due to the time of dipping in water being insufficient to dissolve gallium oxychlorides.

\subsection{Surface morphology study}

Figures 4-7 show the (Nomarski) optical microscopic images of GaAs surfaces after etching in different solutions. Figure 4 shows the optical image of a GaAs surface taken after etching in $\mathrm{H}_{2} \mathrm{SO}_{4} / \mathrm{H}_{2} \mathrm{O}_{2} / \mathrm{H}_{2} \mathrm{O}:: 5: 1: 1$ and then in conc. $\mathrm{HCl}$ for $5 \mathrm{~min}$ and then in deionized water. Conical etch pits are seen which are due to dislocations nearly normal to the $\{100\}$ plane (Abrahams and Buiochhi 1965). Figure 5 shows tails associated with each etch pit, 
which are obtained after etching in $\mathrm{HF}$ at a concentration of $5 \%$ in ethyl alcohol. This kind of behaviour is typical

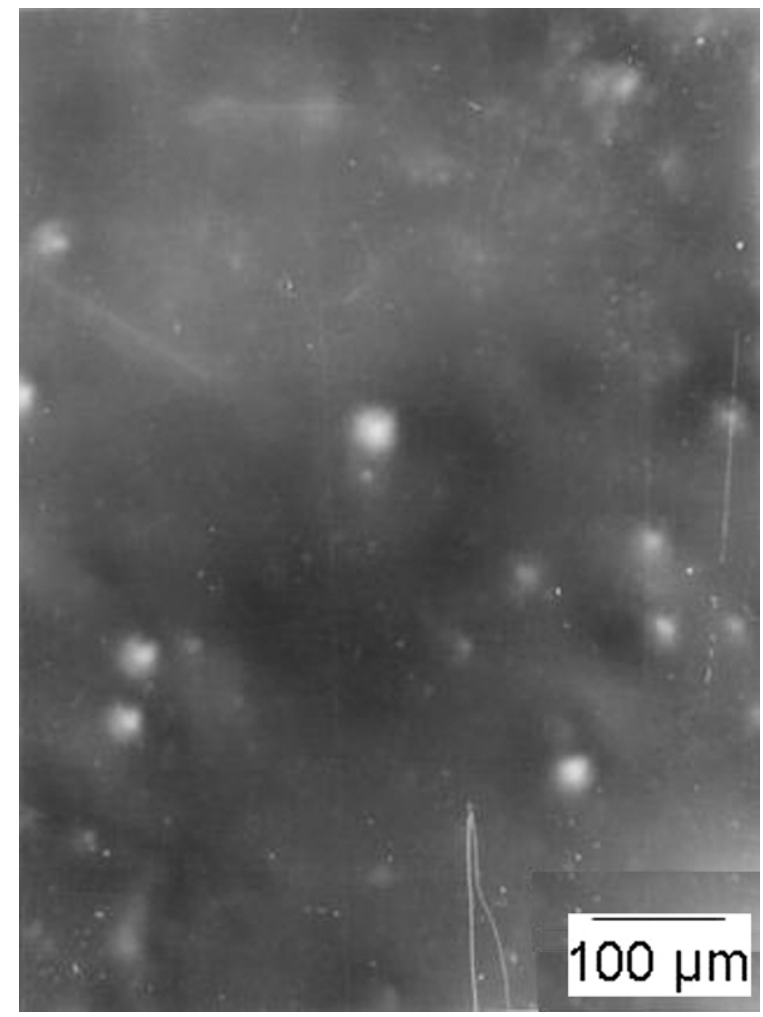

Figure 4. Optical microscopic image of GaAs treated with procedure 1 as described in table 1 .

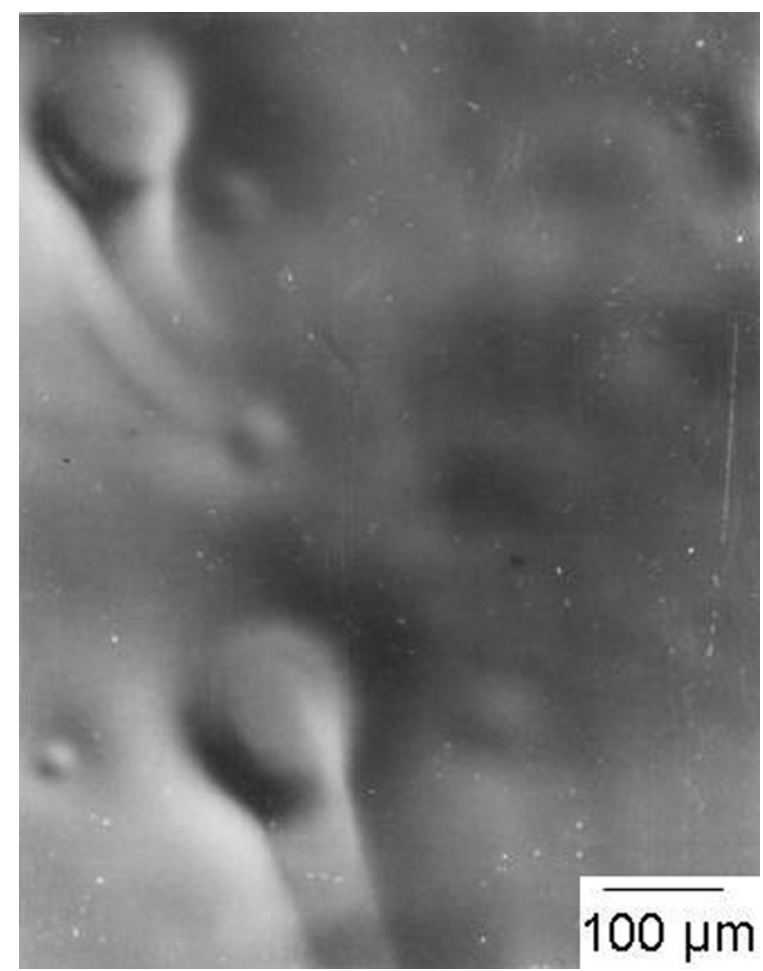

Figure 5. Optical microscopic image of GaAs treated with procedure 2 as described in table 1 . of that expected from a dislocation inclined to the surface. Figure 6 shows the image taken after etching in $\mathrm{HCl}$

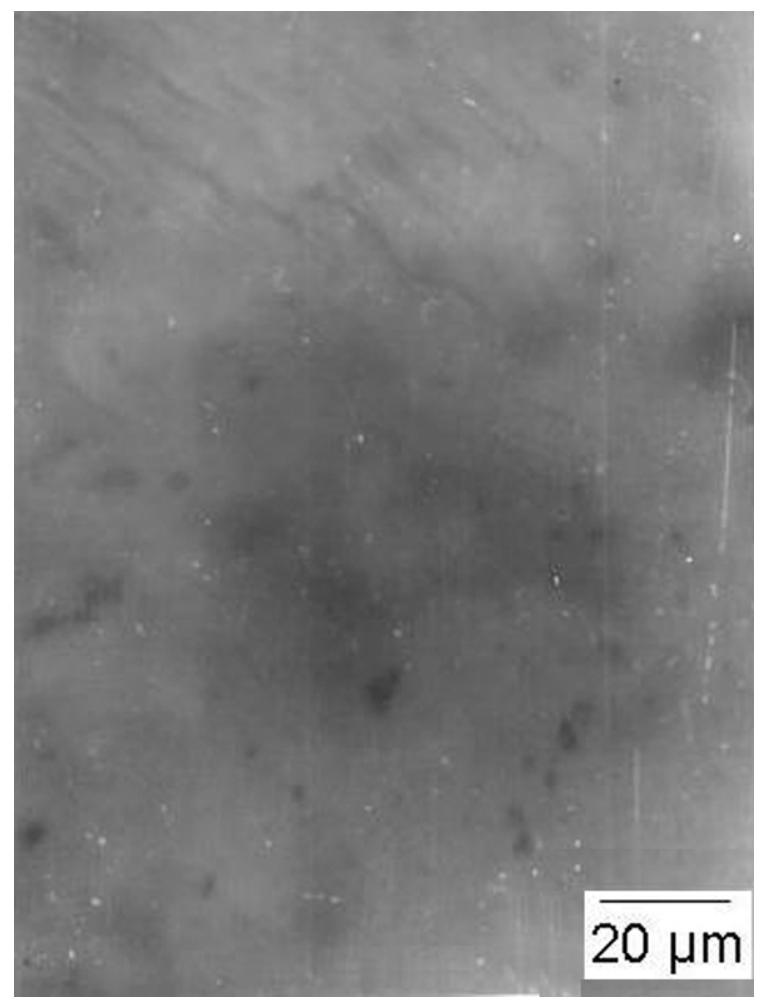

Figure 6. Optical microscopic image of GaAs treated with procedure 3 as described in table 1 .

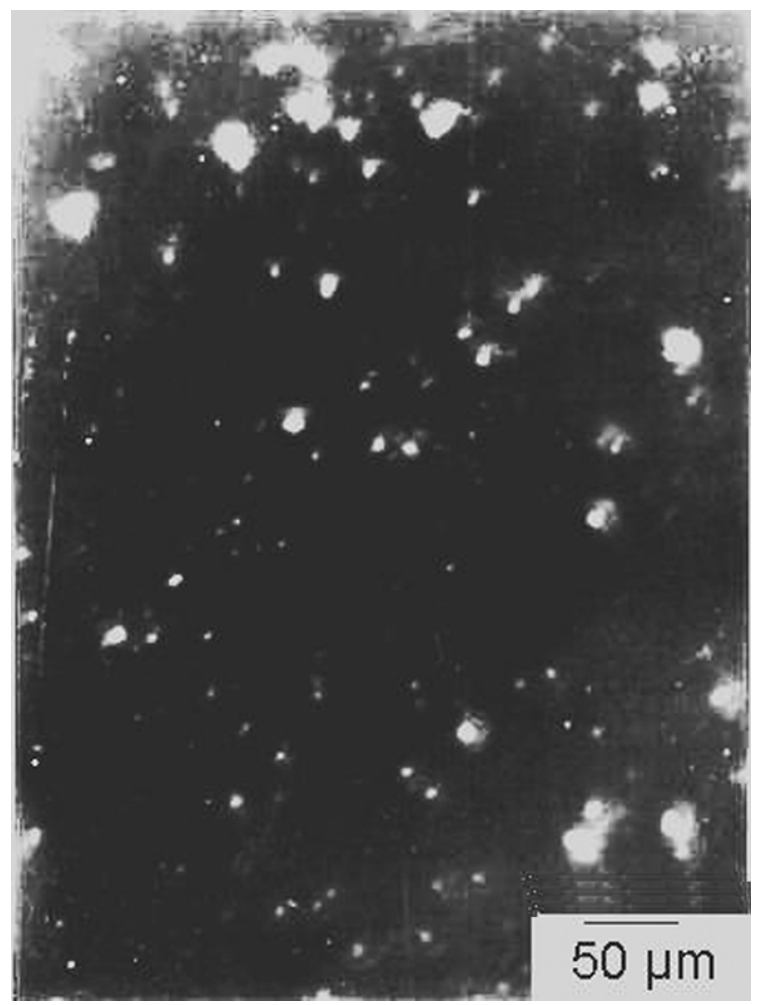

Figure 7. Optical microscopic image of GaAs treated with procedure 4 as described in table 1 . 
solution for $10 \mathrm{~min}$ and then in deionized water for $10 \mathrm{~s}$. This figure reveals relatively long dislocation segments lying in the $\{100\}$ plane. Figure 7 is the image taken from the $\mathrm{GaAs}$ surface after etching in only $\mathrm{HCl}$ solution for $10 \mathrm{~min}$. Conical etch pits along with some foreign particles (dust) are seen on this surface.

\section{Conclusions}

From the above study it is seen that, except for the first procedure (generally used), all the other three processes used for etching GaAs produce an As-rich surface. Also, it is seen that the second method which uses HF-ethanol mixture produces oxide free (no Ga or As oxide) As-rich surfaces and in other procedures no arsenic oxide is observed. From the optical microscopic study, it is seen that different types of etch pits are produced due to different solutions and from which dislocations (normal, inclined and parallel to the plane of observation) are revealed.

\section{Acknowledgements}

One of the authors (AC) thanks the Council of Scientific and Industrial Research (CSIR), India, for providing a scholarship to pursue this work. We are grateful to $\mathrm{Mr}$ Santosh Chowdhury, Institute of Physics, Bhubaneswar, for assistance with XPS.

\section{References}

Abrahams M S and Buiocchi C J 1965 J. Appl. Phys. 362855 Bertrand P A 1981 J. Vac. Sci. Technol. 1828

Chang C C, Citrin P H and Schwartz B 1977 J. Vac. Sci. Technol. 14943

Cho A Y 1983 Thin Solid Films 100291

Cho A Y and Tracy Jr J C 1976 United States Patent 3969164

Cho A Y, Casey H C, Radice C and Foy P W 1980 Electron Lett. 1672

http://www.phy.cuhk.edu.hk/ surface/XPSPEAK/

Massies J and Contour J P 1985 J. Appl. Phys. 582

Shirley D A 1972 Phys. Rev. B5 4709

Sherwood P M A 1984 Practical surface analysis (New York: J. Wiley \& Sons) p. 445

Song Z, Shogen S, Kawasaki M and Suemune I 1994 Appl. Surf. Sci. 82/83 250

Vasquez R P, Lewis B F and Grunthaner F J 1983a Appl. Phys. Lett. 42293

Vasquez R P, Lewis B F and Grunthaner F J 1983b J. Vac. Sci. Technol. B1 791 